\title{
Effect of SiC Particulate Reinforcement in A356 / LM25 Alloy Composites and in their Hybrids
}

\author{
Sunitha K, Gurusami K
}

\begin{abstract}
LM25/A356 Aluminium Silicon alloy is characterized by high mechanical strength, corrosion resistance, machinabilty and excellent castability. Its prominent usage is found in high performance applications like in the automotive piston, cylinder blocks and heads, valve lifters, alloy wheels, brake pads and also in turbine blades. The prospects in applications of A356 are improved by heat treatment processes. Moreover the production of A356 Aluminium alloy composites renders provision for effectively tailoring the mechanical properties of the material by reinforcing the particulates of different ceramic materials at varying propositions. Although there are wide ranges of ceramic materials that could be potentially reinforced into $A 356$ aluminium alloys, this paper exclusively reviews on SiC particulate reinforced A356 alloy composites and also its hybrid composites fabricated by strir casting method. This paper brings out the researches performed with A356/SiC composites under various experiment conditions to make this aluminium alloy available for other wide applications.
\end{abstract}

For convenience of discussion in this paper, the composite of A356 as matrix, reinforced by $x$ weight \% of Silicon Carbide particles is hereafter referred to as $\mathrm{A356} / x \mathrm{SiC}_{P}$.

\section{INTRODUCTION}

LM25/A356 is a hypoeutectic Aluminium silicon alloy with excellent rated mechanical properties used in automotives, avinoics, structural materials, power plant turbines, food industry etc. A356 alloy composition include Aluminium with other elements such as $\mathrm{Si}-6.5$ to $7.5 \% \mathrm{Mg}-0.2$ to $0.6 \% \mathrm{Fe}$ $0.5 \% \mathrm{Mn}-0.3 \% \mathrm{Cu} 0.2 \% \mathrm{Zn} 0.1 \% \mathrm{~Pb} 0.1 \%$. [22] The important benefit of choosing A356 alloy is that it can be heat treated to achieve the optimum combination of strength and ductility of the material. The composite of A356 can be produced by reinforcing ceramic particles such as $\mathrm{SiC}, \mathrm{Al}_{2} \mathrm{O}_{3}$, $\mathrm{B}_{4} \mathrm{C}, \mathrm{TiB}_{2}, \mathrm{TiC}$, Graphite, etc. The composites of A356 materials find its applications in many high performance duties. Among the various methods of casting production, the stir casting process is rather simpler, less expensive, and is deployed in mass production [23]. This paper reviews the research works carried out in $\mathrm{A} 356 / \mathrm{XSiC}_{\mathrm{P}}$ composites that were processed by the stir casting method.

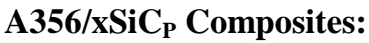

W. Zhou et al. (1997) had made an extensive study on solidification mechanism of $\mathrm{A} 356 / 10 \mathrm{SiC}_{\mathrm{p}}$. The composite was fabricated by two step mixing process which is nothing

Revised Version Manuscript Received on 16 September, 2019.

* Correspondence Author

Sunitha K *, Assistant Professor, St.Peter's Institute of Higher Education And Research

Gurusami K, Assistant Professor, St.Peter's Institute of Higher Education And Research but the solid sate casting process. The paper substantiate better wetting of $\mathrm{SiC}$ particles and better particulate distribution by this two step mixing process without any inclusion of wetting agents. The paper proposes thermal lag model which is responsible for refinement of Aluminium grains that is formation of equiaxed grains by the addition of $\mathrm{SiC}$ particles. Nucleation of eutectic silica takes plates at the sites of $\mathrm{SiC}$ particles is observed and segregation of $\mathrm{SiC}$ particles at the interdentric regions during $\mathrm{Al}$ nucleation is been reported.

S. Naher et al. (2004) had experimented with stir casting parameters of stirring speeds and stirring time at different viscosities of semisolid state $\mathrm{A} 356 / 10 \mathrm{SiC}_{\mathrm{p}}$. It is found that finer micro grain structures casting were obtained in liquid state processing because of high cooling rate whereas in semisolid state processing (metal stirred at viscosity of $300 \mathrm{mPa} \mathrm{s}$ ) micrograph images show larger grain castings.

Higher shear rate i.e stirring speed like $300 \mathrm{rpm}$ for liquid state processing produces greater turbulence and poor distribution of $\mathrm{SiC}$ with porosity in the composites and hence $200 \mathrm{rpm}$ for $16 \mathrm{sec}$ produced good casting. .The liquid state casting produces more porosity compared to semisolid state casting. In semi solid sate casting process the $200 \mathrm{rpm}$ was not sufficient to get homogenised distribution of SiC. The higher stirring speed of $500 \mathrm{rpm}$ in semi solid state reduces the viscosity and aids the breaking down of clusters of $\mathrm{SiC}$, thereby enhancing the stability of the composite slurry. Thus a successful incorporation of $\mathrm{SiC}$ particulates without any wetting agent was achieved when stirring action was performed at semisolid state of $300 \mathrm{mPa}$ s at $500 \mathrm{rpm}$.

Yang Zhiyong et al. (2006) have studied the fracture behavior of $\mathrm{A} 356 / 20 \mathrm{SiC}_{\mathrm{p}}$ composites at room temperature $\left(20^{\circ} \mathrm{C}\right)$ and at high temperatures $\left(200^{\circ} \mathrm{C}, 300^{\circ} \mathrm{C}\right.$ and $400^{\circ} \mathrm{C}$ ) for tensile stress condition. The tensile test result shows that the tensile strength and the Young's Modulus have decreased in either case of base alloy metal and composite with the rise in temperature. When composites are subjected to tensile load at room temperature, the fracture is due to the combination of the ductile failure of metal matrix and brittle failure of ceramic reinforcement particles. As the tensile temperature increases the fracture of composites is due to weakening of bonding interface between the $\mathrm{SiC}$ particles and A356 matrix and hence the whole separation of particulates from metal matrix takes place. These are evident from the microstructure images of fractured surfaces at room temperatures and experimental high temperatures. More of dimples on fractured surface were evident in the images due to the separation of $\mathrm{SiC}$ particles from Aluminium alloy matrix at higher experimental temperatures.

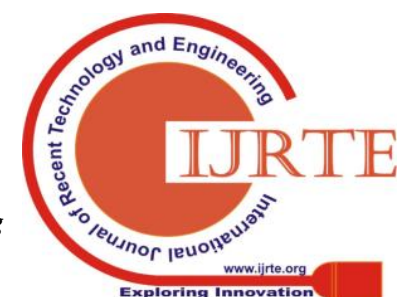


N. Natarajan et al. (2006) had conducted investigation study on the friction and wear behavior of fabricated $\mathrm{A} 356 / 25 \mathrm{SiC}_{\mathrm{p}}$ composite and compared with grey cast iron material at different sliding distance, velocity and load. The composite proves to posses considerable high wear resistance than conventional grey cast iron for brake rotor application. The experimental results show that the frictional force in the composite increases with load and sliding velocity. The friction coefficient of the $\mathrm{A} 356 / 25 \mathrm{SiC}_{\mathrm{p}}$ composite is $20 \%$ greater than the grey cast iron, when subjected to identical wear conditions. Hence the paper infers that this property in $\mathrm{A} 356 / 25 \mathrm{SiC}_{\mathrm{p}}$ contributes for improved braking performance than the grey cast iron.

Dunia Abdul Saheb (2011) had experimented and carried out comparison studies for hardness by varying $\mathrm{SiC}$ particles $(5 \%, 10 \%, 15 \%, 20 \%, 25 \%$, and $30 \%)$ and Graphite particles $(2 \%, 4 \%, 6 \%, 8 \%$ and $10 \%)$ as reinforcements in A356 alloy matrix. Study specimens are fabricated using stir casting method. Increase in hardness had been observed with addition of ceramic materials as reinforcement in weight percentage. During the study, maximum hardness had been obtained at $25 \%$ weight fraction of $\mathrm{SiC}$ and $4 \%$ weight fraction of Graphite. Hardness value of $45.5 \mathrm{BHN}$ had been achieved for $\mathrm{SiC}$ at $25 \%$ weight fraction and hardness value of $74 \mathrm{BHN}$ had been achieved for graphite at $4 \%$ weight fraction. The strong interfacial bond between the graphite particles and aluminium matrix contributes to greater load bearing capacity thereby proving higher hardness strength to the composite when compared to $\mathrm{SiC}$ particle as reinforced composite.

Yunhui Du (2012) had chosen the A356/2.5 $\mathrm{SiC}_{\mathrm{p}}$ composite to study the relation between the stirring speed and the relative radial distribution of $\mathrm{SiC}$ in Aluminium liquid from centre to periphery of the crucible. To visually capture the micro distribution of $\mathrm{SiC}$ in Aluminium liquid, after stirring for selected speed for $8 \mathrm{mins}$, the composite in liquid state is poured into water tanks to prepare water quenched ingots. A nonlinear relationship is identified on varying the stirrer speed and measuring the relative radial distribution of $\mathrm{SiC}$ in microstructure. The researchers have succeeded in deriving an equation for the non linear relation of $\mathrm{SiC}$ distribution and stirring speed.

James B. Min et al. (2013) had conducted extensive study on mechanical property of aluminium alloys of A356 and $\mathrm{Al} 2214$ reinforced with ceramic particles such as $\mathrm{Al}_{2} \mathrm{O}_{3}$, $\mathrm{SiC}$ and $\mathrm{B}_{4} \mathrm{C}$ and compared with his previous experimental work done with various other aluminium alloys. The mechanical properties of particulate reinforced Al 2214 are better than of particulate reinforced Al 356 composites. Considering A356 Aluminium alloy, reinforcement with Alumina particle gives better UTS value of $270 \mathrm{MPa}$ than that of boron carbide particulate reinforcement with UTS value of $226 \mathrm{MPa}$. Similarly the study on fracture toughness also proves that the alumina are better reinforcements with value of $17.8 \mathrm{MPa} V_{\mathrm{m}}$ than that of Boron Carbide with fracture toughness value of $14.1 \mathrm{MPa} \sqrt{\mathrm{m}}$.

The research claims that the low cost availability makes the Alumina, $\mathrm{Al}_{2} \mathrm{O}_{3}$ more attractive as reinforcement besides its density impact on composites. Although the cost of Boron Carbide, $\mathrm{B}_{4} \mathrm{C}$ particulates relatively are on higher end, it favors the applications that demands for weight reduction. Silicon Carbide, $\mathrm{SiC}$ is also low density particulates that induce high thermal conductivity property in the composites.

Akhilesh Jayakumar et al. (2014) had investigated with $\mathrm{A} 356 / \mathrm{SiC}_{\mathrm{p}}$ composites to evaluate its microstructure and mechanical properties. The composite is synthesized by stir casting method. Cylinder of pure Aluminium alloy and A356/SiC composite are fabricated by vertical centrifugal casting. Their macrostructure and mechanical properties were studied.

The pure Aluminium alloy cylinder shows almost homogeneity microstructure from outer to inner periphery, with porosities at the inner walls due to the segregation of low density gas evolved during solidification. The inner wall shows that the primary Aluminium and outer periphery exhibits finer eutectic mixture of $\mathrm{Al}$ - $\mathrm{Si}$ phase due the faster cooling rate. As a result of this finer refinements hardness and tensile strength is high at the outer periphery compared to inner periphery wall of cylinder. Similar such trend but on higher values are found in composite cylinder, due to the presence of high volume of Silicon Carbide particles at the outer periphery than at the inner wall. The composite cylinder inner wall also shows porosities as in pure alloy cylinder.

Like Pan et al. (2017) had studied the thermal fatigue crack behaviour in $\mathrm{A} 356 / 20 \mathrm{SiC}_{\mathrm{p}}$, fabricated by stir casting process. He analysed the initiation and propagation of thermal cracks in the composites. The thermal fatigue specimen with $\mathrm{V}$ - notch was prepared from the composite and subjected to thermal fatigue experiment. The thermal cycle is the alternate heating and cooling of specimen from $250^{\circ} \mathrm{C}$ air heated chamber and $30^{\circ} \mathrm{C}$ water quench. It is observed after 150 cycles the initiation of crack took place. The cracks due to further thermal cycle propagate along the interface of the reinforcement and through the Aluminium matrix. Due to the difference between the coefficient of thermal expansion of $\mathrm{SiC}$ particles and A356 matrix, the thermal stresses are induced at the interfaces of metal matrix and reinforcement particles which cause cracks initiation. In addition, due to the combined effect of interface defects like voids, promote the crack initiation. The voids at the interface initiate the micro cracks and the crack propagation takes place by linking these micro cracks through the preference path of interface [21]. The CTE mismatch that induces thermal stress reduces the strength and weakens the composite. So it is also observed that hardness property of the material reduces with the increase in the number of thermal cycles. After 290 cycles the hardness of the A356/20SiC composite had reduced by $46 \%$.

K.S.R.K. Srinivasa Rao et al. (2017) had fabricated the $\mathrm{A} 356 / \mathrm{SiC}_{\mathrm{p}}$ composites by stir casting method by varying the proportion of $\mathrm{SiC}$ with 5, 10 and 15 weight percentage and investigated the composites for machining and fracture characteristics. It is inferred from the tensile test results that the Yield strength of the A356 composite increases with the increase in the fraction weight percentage of $\mathrm{SiC}$ particle reinforcement. This is due to the pinning of dislocation by $\mathrm{SiC}$ particle in the metal matrix. The Elastic Modulus characteristic proves the same pattern as that of yield strength. The Ultimate Tensile Strength has increased with $5 \% \mathrm{SiC}$ beyond which at the strength decreases due to the promotion of necking phenomenon caused by the larger interfacial area with higher the amount of reinforcement particles in the composites. For the same 
reason it is observed that the percentage elongation also decreases with the increase in reinforcement particles. Further, investigation on components of machining forces, with oblique turning process shows that the better machinability is achieved with addition of $5 \% \mathrm{SiC}$ by weight in A356 alloy. Drastic fall in fracture toughness has also witnessed with addition of $5 \%$ reinforcement by weight. But there on further addition of reinforcement shows trivial influence from those values.

Therefore the study proves that the maximum strength and better machining properties are attained at 5\% $\mathrm{SiC}$ particle reinforcement to A356 alloy at the expense of its ductility and fracture toughness.

Phuriphut Saenpong et al. (2018) produced A356/ $\mathrm{SiC}_{\mathrm{p}}$ composites with $5,10,15$ and $20 \%$ by weight to study the reinforcement compatibility with base alloy and also the hardness properties. The SEM images depict the evidence of well bonded $\mathrm{SiC}$ particulates and Aluminium metal matrix interfaces upto $15 \mathrm{wt}$ \% of reinforcements. Whereas for 20 wt. \% of $\mathrm{SiC}$ the SEM images shows fines cracks at the interfaces of particulate edges and metal matrix. This is due to high cooling rate induced due to increased amount of reinforcing phase. The high cooling rates sets up internal stress which may lead to fine cracks around the particulates in metal matrix. Brinell Hardness tests also prove that the hardness value has increased with increase in weight percentage of $\mathrm{SiC}$ expect for the $20 \mathrm{wt}$. \% due to presence of fine interfacial cracks.

Maciej Dyzia (2018) had done an extensive work on $\mathrm{AlSi} 7 \mathrm{Mg} 2 \mathrm{Sr} 0.03 / \mathrm{SiC}_{\mathrm{p}}$ which is a composition very near to A356 Aluminium alloy with Magnesium for wetting and Strontium $(\mathrm{Sr})$ as modifier. His experiments also confirms that addition of $\mathrm{SiC}$ has improved the wear characteristics, as the $\mathrm{SiC}$ worn out during abrasion are pressed against the matrix alloy and thereby strengthen the composite to withstand the wear.

\section{Nano Composites:}

Like any other alloy materials, many researchers have researched with A356 alloy reinforced with $\mathrm{SiC}$ nano particles and studied the characteristics behaviour of composites by changing the casting process parameters and evaluating the mechanical properties of the composites.

A. Dehghan Hamedan et al. (2012) had experimented with changing the stir casting parameters during the production of $\mathrm{A} 356 / 1 \mathrm{SiC}_{\mathrm{p}}$ composite, where the reinforced $\mathrm{SiC}$ particles is nano sized. They had fabricated composites by varying the stirring speed and stirring temperature and studied their mechanical properties. It is found that the tensile and the compressive strength property of the composite have increased for stirring temperature range of $650-750{ }^{\circ} \mathrm{C}$ at the stirring speed of $700 \mathrm{rpm}$. Md.Tanwir Alam et al. (2014) had also proclaimed the same with his research findings using analysis of variance tool to analyse the stir casting parameters and mechanical properties.

Md. Tanwir Alam et al. (2017) had carried out experiments with nano sized $\mathrm{SiC}$ particles reinforcements in A356 by stir casting method The yield strength and ultimate strength have increased about more than $40 \%$ than the base alloy with decrease in the percentage elongation and toughness by $25 \%$ and $5.5 \%$ respectively.
Donanta Dhaneshwara et al. (2017) had also investigated the effect of nano sized SiC particulates in very minor weight proportions in A356 alloy matrix. Their mechanical properties testing results also confirms that there is significant increase in the UTS, hardness and wear resistance at the expense of the elongation property. Their research also includes the effect of strontium (Al-15Sr) at $0.046 \%$ which is added as modifier during fabrication of composite inorder to change the eutectic network of $\mathrm{Al}-\mathrm{Si}$ from coarse flakes to fine globular microstructure.

\section{Hybrid Composites:}

The research results show that the possibility of the hybrid composite of other ceramic particles along with $\mathrm{SiC}$ particles reinforced in the metal matrix of A356 alloy is as favorable as in any other Aluminium alloy.

G. Elango et al. (2013) had conducted wear testing experiments with A356 and its hybrid composites of $\mathrm{SiC}$ and $\mathrm{TiO}_{2}$ with different weight fractions. A356/SiC, $\mathrm{A} 356 / \mathrm{SiC} / 2.5 \mathrm{TiO}_{2}$ and $\mathrm{A} 356 / \mathrm{SiC} / 5 \mathrm{TiO}_{2}$ are manufactured by stir casting method.

The pin on disc sliding wear tests were performed at room temperature for different applied loads of $29.43 \mathrm{~N}$ (3Kgf), 39.24N (4Kgf) and $49.05 \mathrm{~N}$ (5Kgf) for a total sliding distance $628 \mathrm{~m}$ at a constant sliding speed of $1.04 \mathrm{~m} / \mathrm{s}$. wear resistance of the A356 alloy composite increases with increase in the weight fraction of ceramic particles. The hybrid composition of $\mathrm{A} 356 / \mathrm{SiC} / 5 \mathrm{TiO}_{2}$ exhibit high wears resistance property. Its coefficient of friction is less when compared with its base alloy matrix and binary composite. Due to hardened nature and lubricating property of $\mathrm{TiO}_{2}$, its high weight fraction incorporation in Aluminium Silica Carbide composite results in high wear resistance capability.

Dora Siva Prasad et al. (2014) had reported that A356 alloy when reinforced with equal proportion of $\mathrm{SiC}$ and Rice Husk Ash (RHA) particulates in weight fractions of 2, 4, $6 \& 8$, the hardness, yield strength and ultimate strength have shown increase in the trend with increase in the weight percentage of reinforced particles. The reported reason for increase in the strength is due to the increased dislocation density which is caused by the increase in the reinforcements proportions and thermal mismatch among them base alloy and reinforcements. The percentage elongation decreased with increase in the weight percentages of reinforcements.

A study of age hardening on base alloy and composites was also performed to investigate the variation in their hardness property. The experiments inferred that during aging treatment precipation hardening is accelerated by addition of reinforcements thereby increasing the Brinell hardness values. The reinforcements also influenced the time factor of attaining maximum hardness value, by showing reduction in time when compared to the base alloy age hardening. The investigation on thermal property proved that CTE found to be reduced in hybrid composites with high volume percentage reinforcements.

A. J. Dolata et al. (2016) had analysed the cooling curves of Al7Si7Mg base alloy, Hybrid composite $\mathrm{A} 17 \mathrm{Si} 2 \mathrm{Mg} / 5 \mathrm{SiC} / 2 \mathrm{Cg}$ (where $\mathrm{Cg}$ is Glass Carbon particles) with $0.03 \% \mathrm{Sr}$. The investigation on composite shows that the addition of Magnesium and Strontium reduces the cooling temperature, disrupts the oxide film from Aluminium surface,

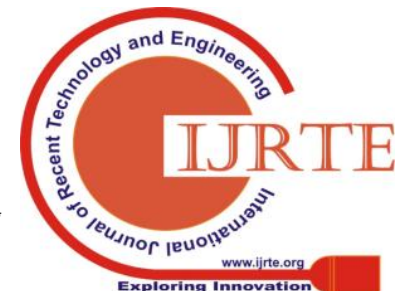


reduces the surface tension and also change the eutectic network of Al-Si from coarse acicular structure to soft globular microstructure.

Dhanasekaran $\mathbf{R}$ et al. (2017) had synthesized hybrid composites of A356 with particle reinforcements of $\mathrm{SiC}$ and $\mathrm{Al}_{2} \mathrm{O}_{3}$ and studied their hardness property with samples containing different percentage composition. The hardness testing was conducted on particle reinforced hybrid composites $\mathrm{A} 356 / 10 \mathrm{SiC} / 10 \mathrm{Al}_{2} \mathrm{O}_{3}, \mathrm{~A} 356 / 15 \mathrm{SiC} / 10 \mathrm{Al}_{2} \mathrm{O}_{3}$ and $\mathrm{A} 356 / 20 \mathrm{SiC} / 10 \mathrm{Al}_{2} \mathrm{O}_{3}$ showed hardness values of $100 \mathrm{BHN}$, $108 \mathrm{BHN} 107 \mathrm{BHN}$ respectively for $3000 \mathrm{~N}$ and $5 \mathrm{~mm}$ diameter of carbide ball in accordance with ASTM E 10 standards. It is inferred that increase in weight percentage of $\mathrm{SiC}$ increases the hardness value only upto certain value after which for increase to $20 \%$ weight fraction, the hardness value decreases. This may be due to the increase in the ceramic fraction in metal matrix leads to more brittle composites that reduces the hardness property.

\section{CONCLUSION}

Though the paper stringently focuses on the composite of A356/ LM25 reinforced with Silicon Carbide particles and also few of their hybrid composites, a vivid review has made on the same.

- Researchers have proved the metallurgical reasons for compatibility of $\mathrm{SiC}$ in $\mathrm{A} 356$ alloy matrix that proves the enhancement of the strength in the base alloy.

- A356/SiC composite shows improved mechanical properties in yield strength, ultimate tensile strength, hardness and wear properties, when compared to the base alloy.

- $\quad$ Two step stirring process or semi solid casting process has proved to overcome the wettability challenge of $\mathrm{SiC}$ in Aluminium Silicon alloy.

- In most of the research the magnesium is used as wetting agent. The strontium is used as modifier by the researchers to soften the eutectic Aluminium Silcon network.

- Like many other metal matrix composites there exhibits a decline in the percentage elongation upon increasing the weight percentage of reinforcement particles.

- There requires more research studies to be done with this composite to improve the fracture toughness property.

- As like RHA, the compatibility of many other natural ceramic materials with $\mathrm{A} 356 / \mathrm{SiC}$ to form hybrid composites are need explored and properties to be studied to extend the applications of this high performance materials.

\section{REFERENCES}

1. W. Zhou and Z. M. Xu "Casting of SiC Reinforced Metal Matrix Composites" Journal of Materials Processing Technology, Vol. 63, pp. 358-363, 1997.

2. S. Naher, D. Brabazon, L. Looney "Development and assessment of a new quick quench stir caster design for the production of metal matrix composites" Materials Processing Research Centre, Dublin, Ireland. Journal of Materials Processing Technology, Vol. 166, pp 430-439, 2004.

3. Yang Zhiyong, Han Jiunmin , Li Weijing, Wang Wenjing , and Kang Suk-Bong "Study on fracture behavior of SiCp/A356 composites" Rare Metals, Vol. 25, Spec. Issue, pp. I68 -173, December 2006.

4. N. Natarajan, S. Vijayarangan and I. Rajendran "Wear behaviour of A356/25SiCp aluminium matrix composites sliding against automobile friction material" Wear, Vol. 261, pp. 812-822, 2006.

5. Dunia Abdul Saheb, "Aluminum Silicon Carbide And Aluminum Graphite Particulate Composites" ARPN Journal of Engineering and Applied Sciences Vol. 6, No. 10, October 2011

6. Yunhui Du, Peng Zhang, Jun Zhang and Shasha Yao "Radial Distribution of SiC Particles in Mechanical Stirring of A356-SiCp Liquid" Journal of Material Science \& Technology, Vol.28, pp. 951-955, 2012.

7. James B. Min and James A. Cornie "Fracture Analysis of Particulate Reinforced Metal Matrix Composites" NASA Center for Aerospace Information, NASA/TM-2013-217871, May 2013.

8. Akhilesh Jayakumar and Mahesh Rangaraj "Property Analysis of Aluminium (LM-25) Metal Matrix Composite" International Journal of Emerging Technology and Advanced Engineering, Vol. 4, Issue 2, February 2014.

9. Like Pan, Jianmin Han, Zhiyong Yang, Xiang Li, Jialin Wang, Zhiqiang $\mathrm{Li}$ and Weijing $\mathrm{Li}$ "Thermal fatigue crack behavior of $\mathrm{SiCp} / \mathrm{A} 356$ composites prepared by stirring casting" Results in Physics, Vol. 7, pp. 927-933, 2017.

10. K.S.R.K. Srinivasa Rao and S. Kamaluddin, "Machining and fracture characteristics of SiC reinforced A356 alloy composites" International Journal of Advanced Trends in Engineering, Science and Technology (IJATEST) Vol.2, Issue 4, July.2017.

11. Phuriphut Saenpong, Sukangkana Talangkun, Teerawat Laonapakul and Apichart Boonma, "Microstructures and hardness of A356-SiC composites produced by the mechanical stir casting" Materials Today: Proceedings 5, (Thailand International Metallurgy Conference) pp. 9489-9496, 2018.

12. Maciej Dyzia “Aluminum Matrix Composite (A1Si7Mg2Sr0.03/SiCp) Pistons Obtained by Mechanical Mixing Method" Materials, Vol. 11, issue 8, 2018.

13. A. Dehghan Hamedan, M. Shahmiri "Production of A356-1 wt\% SiC nanocomposite by the modified stir casting method" Materials Science \& Engineering A, Vol.556, pp. 921-926, 2012.

14. Md.Tanwir Alam and Akhter Husain Ansari "Characterization and Behaviour of Aluminium Silicon Carbide Composite Casting" Indian Foundry Journal, Vol. 60, pp. 36-42, 2014

15. A. J. Dolata , M. Dyzia, S. Boczkal" Influence of the $\mathrm{Sr}$ and $\mathrm{Mg}$ alloying additions on the bonding between matrix and reinforcing particles in the AlSi7Mg/SiC-Cg hybrid composite" Archives Of Metallurgy And Materials , Vol. 61, No 2, pp. 651-656, 2016.

16. Md. Tanwir Alam, Sajjad Arif and Akhter Husain Ansari "Mechanical Behaviour and Morphology of A356/SiC Nanocomposites Using Stir Casting" IOP Conf. Series: Materials Science and Engineering pp. 25-235, 2017.

17. G. Elango and B.K.Raghunath "Tribological Behavior of Hybrid $(\mathrm{LM} 25 \mathrm{Al}+\mathrm{SiC}+\mathrm{TiO} 2)$ Metal Matrix Composites" International Conference on Design And Manufacturing, Procedia Engineering, Vol. 64, pp. $671-680,2013$.

18. Dora Siva Prasad, Chintada Shoba and Nallu Ramanaiah "Investigations On Mechanical Properties Of Aluminum Hybrid Composites" Journal of Material research and Technology, Vol. 3, Issue 1, pp. 79-8, 2014.

19. Donanta Dhaneswara, Anne Zulfia Syahrial and Muhammad Tsabit Ayman "Mechanical Properties of Nano SiC-Reinforced Aluminum A356 with Sr Modifier Fabricated by Stir Casting Method" Procedia Engineering, Vol. 216, pp. 43-50, 2017.

20. Dhanasekaran R, SaiKrishna N, Santosh M, Pallavi P, Sreenatha Reddy S "Study of Hardness of Aluminium(LM25) Composite" International Journal of Engineering Research And Advanced Technology, Vol. 3, Issue 5, May 2017.

21. Mohammad M. Ranjbaran "Experimental investigation of fracture toughness in Al 356-SiCp aluminium matrix composite" American Journal Of Scientific And Industrial Research, Vol.1(3), 549-557, 2010.

22. MRT castings "Complete Guidelines for Manufacture with LM25 alloys" 2017

23. Raj Kumar Singh, Amit Telang, S. Das "Microstructure and Mechanical Properties of Al-Si Alloy in As-cast and Heat Treated Condition" American Journal of Engineering Research, Vol.-5, Issue-8, pp-133-137, 2016. 
24. Nikhilesh Chawla, and Yu-Lin Shen "Mechanical Behavior of Particle Reinforced Metal Matrix Composites" Advanced Engineering Materials, Vol. 3, Issue 6, pp. 357-370, 2001

25. Manikandan.R, Gunasekaran. D Naveenkumar.M, and Dr.Murali Manohar.R "Design and Analysis of Aluminium Alloy -Tib2 and Silicon Carbide Composite Piston" International Journal of Advanced Research in Basic Engineering Sciences and Technology, Vol.3, Issue.24, pp. 828-835 March 2017.

26. Abino John Jenson T Mathew Vasdev Malhotra Nitin Dixit "Design and Analysis of Piston by $\mathrm{SiC}$ Composite Material" International Journal for Innovative Research in Science \& Technology, Vol. 1, Issue 12, pp. 578-590 May 2015 